\title{
Promoting Mental Well-Being Through Social-Emotional Learning in Schools: Examples from British Columbia
}

\author{
Shelley Hymel, Angela Low, Lindsay Starosta, Randip Gill, and \\ Kimberly Schonert-Reichl \\ University of British Columbia
}

\begin{abstract}
Social and emotional learning is increasingly recognized as playing an important role in the promotion of positive mental health in schools. In 2012, the Mental Health Commission of Canada identified child and youth mental health as a priority for the transformation of mental health systems in Canada. To this end, comprehensive efforts to promote positive social and emotional development in schools and to foster safe and caring school environments are urgently needed. This paper highlights the multi-faceted approach undertaken in British Columbia over the past decade to promote positive mental health through social-emotional learning in schools.
\end{abstract}

Keywords: mental health, well-being, social-emotional learning, children/youth

\section{RÉSUMÉ}

L'apprentissage socio-émotionel est de plus en plus reconnu comme jouant un rôle important dans la promotion de la santé mentale en milieu scolaire. Étant donné que la promotion de la santé mentale chez les enfants et les adolescents a été identifiée comme priorité par le Commission de la santé mentale du Canada, il est urgent de déployer des efforts significatifs afin de promouvoir le développement socio-émotionnel

Shelley Hymel, Department of Educational and Counselling Psychology and Special Education, Faculty of Education, University of British Columbia, Vancouver, British Columba; Angela Low, Department of Educational and Counselling Psychology and Special Education, Faculty of Education, University of British Columbia, Vancouver, British Columba; Lindsay Starosta, Department of Educational and Counselling Psychology and Special Education, Faculty of Education, University of British Columbia, Vancouver, British Columba; Randip Gill, Department of Educational and Counselling Psychology and Special Education, Faculty of Education, University of British Columbia, Vancouver, British Columba; Kimberly Schonert-Reichl, Department of Educational and Counselling Psychology and Special Education, Faculty of Education, University of British Columbia, Vancouver, British Columba.

Our work in the area of social-emotional learning has been supported by the Edith Lando Charitable Foundation and the Jacqueline Farquhar Endowment for Children's Mental Health.

Correspondence concerning this article should be addressed to Dr. Shelley Hymel, Faculty of Education-ECPS Department, University of British Columbia, 2125 Main Mall, Vancouver, BC, V6T 1Z4, Email: shelley.hymel@ubc.ca 
dans les écoles pour favoriser des milieux sécuritaires et accueillants. Ce document souligne et résume l'approche à multiple facettes déployée depuis dix ans en Colombie Britannique afin de promouvoir la santé mentale via l'apprentissage socio-émotionnel en milieu scolaire.

Mots clés : santé mentale, bien-être, compétences sociales et émotionnelles, enfants/adolescents

Each year, one in five Canadians experience some form of mental health or addictions problem, with estimates that, by age 40, half of all Canadians will experience such challenges (Smetanin et al., 2011). The cost of mental health problems is staggering. Canada spends about $\$ 14.4$ billion annually on the treatment of mental illness (Joubert \& Stephens, 2001), with projections that, by 2020, mental illness will represent the country's leading healthcare cost (Canadian Psychiatric Association, 2001). Equally troublesome are the indirect costs to society, as individuals with mental disorders are far more likely to be among the unemployed, the incarcerated, and the homeless. Half of a million Canadians are unable to work each week because of disabilities due to mental and/or behavioural disorders or absenteeism due to mental illness (Dewa, Chau, \& Dermer, 2010; Alberta Canada Institute of Health Economics, 2007). In the Canadian penal system, 13\% of men and $29 \%$ of women in federal custody self-identify as having mental health problems (Stewart et al., 2009). Among the homeless in Canada, 23 to 74\% report having mental health problems (Canadian Institute for Health Information, 2007).

Although there are multiple approaches to addressing these mental health challenges, a primary focus should be on addressing root causes and contributing factors. Half of all lifetime cases of mental illness start by age 14; 75\% by age 24 (Kessler, Berglund, Demler, Jin, \& Walters, 2005). Although an estimated 20 to $25 \%$ of children and youth in North America have mental health problems that are significant enough to warrant social services, the vast majority do not receive such services (Estrada \& Pinsof, 1995; Illback, 1994; Waddell, McEwan, Shepherd, Offord, \& Hua, 2005). Given these statistics, it is appropriate that child and youth mental health is identified as a priority in the 2012 Mental Health Strategy for Canada (Mental Health Commission of Canada, 2012). Recognizing that childhood is an important window for the promotion of mental well-being and the prevention of mental illnesses, and that schools are an important context for reaching children and their families, the 2012 strategy calls for comprehensive, school-wide initiatives that promote positive social and emotional development, foster safe and caring school environments, and reduce stigma and other risk factors such as bullying. In this paper, we provide an overview of the links between mental well-being and social-emotional learning (SEL) in schools and provide examples of the multi-faceted approach undertaken in British Columbia over the past decade to promote positive mental health through education.

\section{Changing Conceptions of Mental Health}

Conceptions of mental health have changed significantly over the past decades (Weare, 2010), shifting from notions of mental "health" as the absence of mental disorders to a focus on mental well-being as a positive state that everyone can attain. The World Health Organization (2010, p.1) defines mental health as a "state of well-being in which an individual realizes his or her own abilities, can cope with the normal 
stresses of life, can work productively and is able to make a contribution to his or her community." In response, there is growing emphasis on promoting mental well-being through "universal" approaches aimed at all individuals, and not just "targeted" practices aimed at helping individuals experiencing mental illness (Weare, 2010).

Although many welcome this shift, we cannot ignore or reduce efforts to address mental disorders; such a focus is critical and must be maintained. To this end, scholars have argued for a dual-factor model of mental health (see Suldo, 2016) in which psychopathology and mental well-being are considered distinct. Thus, complete mental health is defined as the presence of few symptoms of psychopathology coupled with an intact sense of subjective well-being. Summarizing research demonstrating the utility of this dual-factor model, Suldo reports that, across elementary, secondary, and university samples, $57-78 \%$ of individuals demonstrate complete mental health (low psychopathology, high subjective well-being), and 4-17\% show elevated levels of psychopathology but average to high levels of subjective well-being. Another 8-19\% of individuals are identified as "vulnerable" or "at risk" (low subjective well-being but no clear symptoms of psychopathology), and 8-17\% are identified as "troubled" or "mentally unhealthy" (low subjective wellbeing, elevated psychopathology). Such findings underscore the need to both promote mental well-being in all children, and provide support and clinical services to individuals experiencing mental health difficulties. In doing so, we can not only reduce the likelihood of mental disorders through prevention and early intervention, but also provide safe and caring contexts in which children and youth with mental health difficulties are supported.

Concurrently, increasing emphasis has been placed on schools to focus on social-emotional competencies and mental health literacy, in addition to fostering academic growth (e.g., Weare, 2000, 2010). Although teachers do not have the training needed to diagnose or treat mental disorders, as adults working on the front lines they play a critical role in identifying youth at potential risk for mental health difficulties. To provide effective monitoring, however, mental health literacy must become a focus in teacher training and professional development. Promoted nationally in Canada by Dr. Stan Kutcher at Dalhousie University (Kutcher, 2015; www.teenmentalhealth.org/), mental health literacy includes four distinct but related components: (a) providing educators with a better understanding of mental disorders and their treatment, (b) decreasing the stigma associated with mental health difficulties, (c) understanding how to foster and maintain good mental health and well-being, and (d) helping students to seek help effectively when needed.

In promoting mental health literacy, SEL has been increasingly recognized as a foundation for fostering positive mental health in educational settings (Greenberg, Domitrovich, \& Bumbarger, 2001; Sklad, Diekstra, de Ritter, Ben, \& Gravesteijn, 2012; Wells, Barlow, \& Stewart-Brown, 2003). Popularized by the Collaborative for Academic, Social and Emotional Learning in the United States (CASEL, www.casel.org), SEL is defined as "the process through which we learn to recognize and manage emotions, care about others, make good decisions, behave ethically and responsibly, develop positive relationships and avoid negative behaviors" (Durlak, Weissberg, Domitrovich, \& Gullotta, 2015; Zins, Bloodworth, Weissberg, \& Walberg, 2004) and includes five areas of competence: self awareness, social awareness, self-management, relationship skills, and responsible decision making. These competencies develop very gradually over the time children are in school (Schonert-Reichl \& Hymel, 1996) and are recognized as "master skills" underlying much of our behaviour. 
A recent meta-analysis (Durlak, Weissberg, Dymnicki, Taylor, \& Schellinger, 2011) showed that participation in school-based SEL programs yields significant positive effects on social-emotional competencies; attitudes about self, others, and school; and behaviour (increased prosocial behaviour, decreased conduct problems, and internalizing difficulties), as well as improvements in academic performance. Moreover, longitudinal research (Hawkins, Kosterman, Catalano, Hill, \& Abbott, 2005) has demonstrated that the impact of a well-designed and executed, school-based elementary SEL program was evident 12 to 15 years later. Those who had participated in the program, now young adults, showed higher educational attainment, better employment, and better mental health (reduced social phobia and suicidal thoughts).

From a cost-benefit perspective, schools are an ideal context for promoting social-emotional competencies (Zins et al., 2004), where we can reach a majority of youth — early on and repeatedly. Moreover, a recent analysis conducted by the Center for Benefit-Cost Studies in Education at Columbia University (Belfield et al., 2015) has documented a substantial economic return on investment for SEL programs, with a benefit-cost ratio of $\$ 11$ dollars in return for every dollar spent.

Multiple stakeholders in BC have recognized the importance of SEL, leading to a multi-faceted approach to promoting SEL through education. Although it is beyond the scope of this paper to capture all of the ways that teachers, parents, and communities teach children these essential life skills, we summarize below a variety of efforts to promote SEL through education, including province-wide educational initiatives, influential local programs and events, and school-community collaborations.

\section{Province-Wide Promotion of SEL Through Education}

Among the many province-wide initiatives aimed at promoting SEL and mental well-being in schools, we highlight three: the newly revised $\mathrm{BC}$ school curriculum, pre-service teacher education efforts, and direct efforts to address the challenges of bullying and anxiety.

SEL in the BC Curriculum. Historically, social development has long been a focus within the BC school system. The 1989 Mandate for the School System specified human and social development as major goals of education. In 2001, social responsibility was established as one of four "foundational skills," along with reading, writing, and numeracy. Most recently, SEL has been formally promoted by the British Columbia Ministry of Education (2015), in a revised curriculum first implemented in elementary schools in the 2016-2017 school year, and in secondary schools the following year (2017-2018). In an effort to equip students with the skills and knowledge needed to succeed in today's world, the new curriculum acknowledges non-academic competencies, including SEL, as critical for success both academically and in life. Specifically, the new curriculum specifies three "core" competencies that encompass a broad range of skills: communication, creative and critical thinking, and personal and social responsibility. Personal and social responsibility competencies include a focus on positive personal and cultural identity, personal awareness and responsibility, and social responsibility, within which essential social-emotional skills such as recognizing and regulating emotions, perspective taking, building positive relationships, respectful behaviour, and social problem solving are explored. Although still in an early stage of development and implementation, the new $\mathrm{BC}$ curriculum represents an important step in formally promoting mental well-being in children across the province through SEL in schools. 
SEL in BC Teacher Education. With SEL embedded as one of the core competencies within BC's new curriculum, it becomes critical to integrate the science and practice of SEL into teacher preparation programs. According to a recent scan (Schonert-Reichl, Hanson-Peterson \& Hymel, 2015), promotion of SEL is not a major focus of preservice teacher education programs in the United States, despite evidence that teacher beliefs about, and confidence in, their knowledge of SEL has significant implications for both the students they teach (e.g., Jennings \& Greenberg, 2009) and their own job satisfaction (Collie, Shapka, \& Perry, 2012). To investigate the extent to which SEL is promoted in teacher education in BC, a similar scan was conducted of programs in BC that prepare teachers for the public school system. These nine programs, approved by the BC Teacher's Council, include Simon Fraser University (SFU), Trinity Western University (TWU), Thompson Rivers University (TRU), University of the Fraser Valley (UFV), University of British Columbia-Vancouver (UBC-V), University of Northern British Columbia (UNBC), University of Victoria UVIC, University of British Columbia-Okanagan (UBC-O) and Vancouver Island University (VIU).

Following the framework used by Schonert-Reichl et al. (2015), we scanned for content and processes that support the development of five competencies delineated by CASEL (self-awareness, self-management, social awareness, relationship skills, and healthy decision making) across three dimensions: (1) the socialemotional learning of students, (2) the social-emotional competencies of teachers, and (3) the learning context (e.g., the classroom and school contexts, school-family-community partnerships). Data was gathered through online program and course descriptions, as well as materials (e.g., handbooks) and information gathered from faculty members when available.

A primary finding from this scan was that, at the time of this writing, the vast majority of programs did include an explicit focus on SEL. Five programs highlighted specific goals or learning outcomes focused on promoting social-emotional competencies in students and teachers. All nine programs included courses that provided information and strategies for fostering SEL, covering a range of topics, including emotional literacy/learning, classroom social dynamics, student motivation, interpersonal relationships, social skill instruction, fostering inclusiveness, and conflict resolution.

Each teacher training program addresses this focus in a somewhat different way. Working in collaboration with Dr. Stan Kutcher to promote mental health literacy in teacher training, UBC-V requires all teacher candidates to attend an introductory workshop on mental health literacy and/or SEL, providing an initial "lens" which students carry with them throughout their training. The UBC-V program also includes a short, required course for all teacher candidates on Creating Caring Classroom Communities, which explores the science behind SEL, emphasizes the importance of relationships for learning and prevention of problems, and provides strategies for community building and conflict resolution. Similarly, UVIC offers a course on promoting prosocial behaviour, including strategies for addressing bullying and aggressive behaviour, and the promotion of peacemaking and restorative practices. UNBC offers a course that helps teacher candidates develop classroom and school-wide strategies for fostering social responsibility in their students. TRU offers a course on Health and Career Education that covers students' emotional and social development, and discusses strategies for helping students acquire the knowledge, skills, and attitudes needed to make good personal decisions. VIU offers a similar course on Emotional Learning and SFU offers a course on the Social Lives of Schoolchildren. UFV and TWU have embedded SEL theories and strategies into core program courses. UBC-O offers courses on building positive learning environments, and addressing the social-emotional 
needs of diverse learners. Almost every program included courses or information that addressed the learning context (e.g., courses on classroom management). Of note are courses in eight of the programs that address diversity in the classroom and promote inclusive teaching practices.

Some universities integrate SEL into the broader structure of their teacher education program. For example, the UBC-V Teacher Education program, which divides elementary teacher candidates into "cohorts" that specialize in particular areas, includes two SEL cohorts to provide students with opportunities to integrate SEL throughout their coursework, examine issues and research on SEL, attend additional workshops and presentations on SEL, and complete their practicum in schools with an identified SEL focus. SFU's teacher education program offers a Lifework Module cohort that focuses on addressing social responsibility and social justice in schools.

The social-emotional competencies and well-being of teachers are also emphasized in most of the BC teacher training programs. Specifically, five programs include courses focusing on improving the communication and interpersonal skills of teacher candidates and four programs emphasize the personal well-being of teacher candidates. Of note is TWU's stated learning outcome that their graduates "develop restorative practices to support their personal well-being and the well-being of learners."

Finally, as part of their effort to promote SEL and mental well-being in schools, UBC-V faculty and graduate students have collaborated with several foundations to create a unique online site through which teachers can learn about SEL and mental health: the SEL Resource Finder (www.selresources.com). The website is designed as a "one-stop shop" for educators and anyone who works with children and youth to learn about how to foster SEL and mental well-being in any educational setting. The SEL section of the site provides links to help educators learn about, apply, and assess strategies for promoting various socialemotional competencies; the Mental Health section provides links through which educators can learn about mental disorders and about ways to support students experiencing mental health difficulties.

Efforts to Address Challenging Behaviour through SEL. In keeping with the dual process model described earlier, it is also important to recognize efforts to address more challenging behaviours. Here we consider two examples from British Columbia. At the provincial level, the BC Ministry of Education launched the ERASE Anti-bullying program in 2012. ERASE (Expect Respect and A Safe Education) is a comprehensive prevention/intervention strategy designed to enable all schools to address bullying by creating safe, caring, and connected school communities that proactively identify and address threats, personalizing learning and support for students, and building consistent policies and practices across school districts, with strong community partnerships and support. Building upon the province's Safe, Caring and Orderly Schools Strategy first introduced in 2004, ERASE includes a five-year, multi-level training program for educators and community partners, dedicated Safe School coordinators in each district, an anonymous online reporting system (www.reportbullyingbc.edudata.ca), school codes of conduct and provincial guidelines, online resources for parents, formal protocols to guide school-community partnerships, a provincial advisory committee of school and community partners, a dedicated professional development day focused on anti-bullying, and threat assessment training for educators.

Province-wide efforts are also directed toward addressing anxiety, one of the most frequent mental health difficulties reported, with prevalence estimates of $10-22 \%$ in childhood and nearly $30 \%$ across a person's 
lifetime (Dadds, Spence, Holland, Barrett, \& Laurens, 1997; Kessler et al., 2005; Muris, Merckelbach, Mayer \& Prins, 2000). As part of a provincial strategy, AnxietyBC (www.anxietybc.com/), established in 1999, is a non-profit organization that works to raise awareness, promote education, and increase access to evidencebased resources and treatments for anxiety. They provide anxiety plans to help users understand and manage anxiety, relaxation tools for dealing with anxiety (e.g., mindfulness, breathing exercises, visualization strategies, "tense and release" techniques), tips on how to change thinking, and links to numerous self-help resources. Their website also lists anxiety indicators and steps that educators can take to help students deal with anxiety problems.

\section{Community Collaborations}

If it takes a village to raise a child, it is also important to recognize a number of unique community collaborations that have contributed to the promotion of social-emotional competencies through education in BC. We highlight five examples.

Addressing Bullying Using your WITS. Developed under the direction of Dr. Bonnie Leadbeater at UVIC and Tom Woods of the Rock Solid Foundation, the WITS Program (www.witsprogram.ca) is a community-based, anti-bullying program for elementary students (WITS Primary for Grades 1-3, WITS LEADS for Grades 4-6) through which students learn a series of strategies to be used when bullied (walk away, ignore, talk it out, seek help). With a goal of teaching students to manage peer conflict in safe and positive ways, the WITS program brings together schools, families and community members to create learning environments that are responsive to student challenges with bullying. The WITS website offers free resources (online modules, lesson plans/activities, books) that can be easily integrated into daily practice. Students in schools with well-established WITS programs are more likely to identify and report victimization incidents, possibly due to greater awareness, and have higher levels of social responsibility according to teachers (Leadbeater \& Sukhawathanakul, 2011), and demonstrate declines in physical and relational violence (Leadbeater, Hoglund, \& Woods, 2003). WITS is recognized by the Canadian Best Practices Portal as a "best practice" program.

Vancouver's Dalai Lama Center. The Dalai Lama Center for Peace and Education (DLC) is an important community partner that advocates for the integration of SEL into children's learning environments in BC. Established in 2005, the center's mission is to inform, inspire and engage communities to "educate the hearts" of children. Sharing SEL research, knowledge and best practices through influential events such as dialogues with the Dalai Lama and an annual Heart-Mind Conference, the DLC has played a significant role in raising awareness of SEL in British Columbia. The DLC has also developed an online resource (http://dalailamacenter.org/programs/heart-mind-online) that provides educators and families with evidenceinformed tools and information for fostering SEL. Another notable contribution is their development of the Heart-Mind Index, a population-level measure of children's social and emotional well-being, which has been used to facilitate community dialogue and collaboration to improve childhood learning environments.

School-University Collaboration to Promote SEL. SEL-BC is a collaborative network of education leaders from multiple school districts who are responsible for promotion of SEL, directors of community organizations (e.g., the Dalai Lama Centre), and university researchers who have worked together for more 
than a decade to foster SEL, social responsibility and collaborative learning in BC schools. With a mission to "advance and connect research and practice in order to establish and sustain social emotional learning and social responsibility within safe, caring, collaborative and inclusive learning communities," this network has been influential in advocating for, and raising awareness of, the value of SEL in education and provides leadership and builds capacity to support SEL across the province. With the BC Collaborative Learning Association, SEL-BC organizes an annual "Encompass" conference to support teacher professional development. Finally, SEL-BC promotes collaborative research on SEL, with an understanding that practice can inform research as much as research can inform educational practice.

Human Early Learning Partnership. The Human Early Learning Partnership (HELP, www.earlylearning.ca) is an interdisciplinary research institute at UBC-V whose mission is "creating, promoting and applying new knowledge to help children and families thrive." Since 2001, with funding from the BC Ministries of Children and Family Development, Education, and Health, HELP's collaborative, multidisciplinary network of faculty and graduate students have shared their expertise in child development and research methods with government and community partners to create a "greenhouse environment" that encourages integration of multiple perspectives in creating and applying new knowledge to address complex developmental and health issues.

As children's social-emotional competencies and mental well-being become priorities in schools and communities, reliable and valid methods are needed to assess the efficacy of such efforts. One of HELP's strategic priorities is to establish a comprehensive child development monitoring system. To this end, HELP has promoted use of the Early Development Instrument (EDI), a teacher-report survey exploring kindergartener's developmental characteristics and readiness for school. As a follow-up to the EDI, HELP has also developed the Middle Years Development Instrument (MDI), a strength-based, population-level, self-report measure for students in Grades 4 and 7 (Guhn, Schonert-Reichl, Gadermann, Hymel, \& Hertzman, 2012; Schonert-Reichl et al., 2013). The MDI is designed to help educators, community leaders and policy makers track trends in children's social-emotional well-being and developmental assets over time, providing information for decision making aimed at creating healthy social conditions, and integrating social services in ways that optimize child development. Results from these population-level measures are presented in a unique series of geographically mapped reports (http://earlylearning.ubc.ca/maps/) that inform the design and implementation of programs and policies to promote children's well-being. Participating communities also have access to videos, talks, worksheets, community stories, and links to academic research to help them move findings from the EDI/MDI to action.

Promoting SEL through Opera. As a final example, we point to the Vancouver Opera's groundbreaking and technologically innovative chamber opera, Stickboy, based on the life story of Canada's spoken word artist, Shane Koyczan (see www.youtube.com/watch?v=CRxQyWXI7So) and his experiences with bullying and victimization as an adolescent. The opera's premiere in 2014 effectively raised awareness about the complex issue of school bullying and its long-term impact on those involved. Particularly noteworthy, however, is the subsequent development of a one-hour adaptation of Stickboy that was performed in more than 50 secondary school and community venues throughout BC in 2016 (http://stickboyopera.ca/) with accompanying study guides and school activities aimed at helping educators raise awareness about bullying and its impact among teens. Stickboy represents yet another innovative illustration of how BC-based 
community-school collaborations have helped to increase awareness and enhance efforts to address issues of school bullying.

\section{CONCLUSION}

This paper describes efforts to foster SEL and mental well-beiing in British Columbia as examples of how the values and priorities elaborated in the 2012 Mental Health Strategy for Canada are already being put into action in schools. The vibrancy of the field in BC owes much to the dynamic collaboration among universities, school districts and community partners, and the continuing support provided by foundations committed to promoting childhood well-being. The inclusion of SEL in the new BC school curriculum is a big leap towards a more systemic and widespread approach for promoting positive social-emotional development in schools and creating safe and caring, inclusive school environments. However, further efforts are urgently needed to empower and support teachers, school staff, and students to meet these standards.

Building the competencies of educators who teach these skills and administrators who support their efforts, and designing and creating supportive learning environments require additional time, training, tools, and funding. For example, courses focusing on SEL are not currently mandatory in most teacher education programs, nor are SEL workshops a mandated part of teachers' professional development. In many cases, teacher learning and engagement with SEL are left to individual districts and teacher preferences. Greater integration of SEL in teacher training and professional development is necessary for the evidenced outcomes of SEL to be widespread and sustained.

Systematic change also requires dialogue and engagement with relevant stakeholders, including parents. Equally important is the development of systematic efforts to assess progress in this area and the effectiveness of various initiatives undertaken using well-developed, reliable, and valid measures. School-university partnerships, as exemplified by SEL-BC, are especially helpful in this regard. Greater cooperation and dialogue between educators and other community agencies and service providers (e.g., pediatricians, clinicians) are also important for systemic change. As the science and practice of SEL in schools is still evolving, sharing "promising practices" and "lessons learned" is important in moving the field forward. We encourage readers to consider these efforts in $\mathrm{BC}$, and look forward to learning about different approaches towards promoting positive mental health through SEL in schools across Canada.

\section{REFERENCES}

Alberta Canada Institute of Health Economics. (2007). Mental health economic statistics: In your pocket, retrieved from https://www.ihe.ca/advanced-search/mental-health-economic-statistics-in-your-pocket

Belfield, C., Bowden, B., Klapp, A., Levin, H., Shand, R., \& Zander, S. (2015). The economic value of social and emotional learning. NY: Center for Benefit-Cost Studies in Education, Teachers College, Columbia University.

British Columbia Ministry of Education. (2015). Building student success: BC's new curriculum. Retrieved from https:// curriculum.gov.bc.ca

Canadian Institute for Health Information. (2007). Improving the health of Canadians: Mental health and homelessness. Retrieved from http://secure.cihi.ca/cihiweb/products/mental_health_report_aug22_2007_e.pdf

Canadian Psychiatric Association. (2001). Mental illness awareness week guidebook. Ottawa, ON: Canadian Psychiatric Association. 
Collie, R. J., Shapka, J. D., \& Perry, N. E. (2012). School climate and social-emotional learning: Predicting teacher stress, job satisfaction, and teaching efficacy. Journal of Educational Psychology, 104, 1189-1204.

Dadds, M. R., Spence, S., Holland, D. E., Barrett, P. M., \& Laurens, K. R. (1997). Prevention and early intervention for anxiety disorders: A controlled trial. Journal of Consulting and Clinical Psychology, 65, 627-635.

Dewa, C. S., Chau, N., \& Dermer, S. (2010). Examining the comparative incidence and costs of physical and mental health-related disabilities in an employed population. Journal of Occupational and Environmental Medicine, $52,758-762$.

Durlak, J. A., Weissberg, R. P., Domitrovich, C. E., \& Gullotta, T. P. (2015). Handbook of social and emotional learning: Research and practice. NY: Guilford.

Durlak, J. A., Weissberg, R., Dymnicki, A., Taylor, R., \& Schellinger, K. (2011). The impact of enhancing students' social and emotional learning: A meta-analysis of school-based universal interventions. Child Development, 82, 405-432.

Estrada, A. U., \& Pinsof, W. M. (1995). The effectiveness of family therapies for selected behavior disorders of childhood. Journal of Marital and Family Therapy, 21, 403-440.

Greenberg, M. T., Domitrovich, C., \& Bumbarger, B. (2001). The prevention of mental disorders in school-aged children: Current state of the field. Prevention \& Treatment, 4, 1-62.

Guhn, M., Schonert-Reichl, K. A., Gadermann, A. M., Hymel, S., \& Hertzman, C. (2012). A population study of victimization, relationships, and well-being in middle childhood. Journal of Happiness Studies, 14, 1529-1541.

Hawkins, J. D., Kosterman, R., Catalano, R. F., Hill, K. G., \& Abbott, R. D. (2005). Positive adult functioning through social development intervention in childhood: Long-term effects from the Seattle Social Development Project. Archives of Pediatrics \& Adolescent Medicine, 159, 25-31.

Illback, R. (1994). Poverty and the crisis in children's services: The need for services integration. Journal of Clinical Child Psychology. 23, 413, 424.

Jennings, P. A., \& Greenberg, M. T. (2009). The prosocial classroom: Teacher social and emotional competence in relation to student and classroom outcomes. Review of Educational Research, 79, 491-525.

Joubert, N., \& T. Stephens. (2001). The economic burden of mental health problems in Canada. Chronic Diseases in Canada, 22, 18-23.

Kessler, R. C., Berglund, P., Demler, O., Jin, R., \& Walters, E. (2005). Lifetime prevalence and age-of-onset distributions in the National Comorbidity Survey Replication, Archives of General Psychiatry, 62, 593-602.

Kutcher, S. (2015). Mental health and high school curriculum guide: Understanding mental health and mental illness (Updated Edition). Halifax, NS: CreateSpace Independent Publishing Platform.

Leadbeater, B. J., Hoglund, W. L., \& Woods, T. (2003). Changing contexts? The effects of a primary prevention program on classroom levels of peer relational and physical victimization. Journal of Community Psychology, 31, 397-418.

Leadbeater, B., \& Sukhawathanakul, P. (2011). Multicomponent programs for reducing peer victimization in early elementary school: A longitudinal evaluation of the WITS primary program. Journal of Community Psychology, $39,606-620$.

Mental Health Commission of Canada. (2012). Changing directions, changing lives: The mental health strategy for Canada. Retrieved from :https://docs.google.com/viewer?url=https $\% 3 \mathrm{~A} \% 2 \mathrm{~F} \% 2 \mathrm{Fwww}$.mentalhealthcommission. ca\%2Fsites\%2Fdefault\%2Ffiles\%2FMHStrategy_Strategy_ENG.pdf

Muris, P., Merckelbach, H., Mayer, B., \& Prins, E. (2000). How serious are common childhood fears. Behaviour Research and Therapy, 38, 217-228.

Schonert-Reichl, K. A., Guhn, M., Gadermann, A. M., Hymel, S., Sweiss, L., \& Hertzman, C. (2013). Development and validation of the Middle Years Development Instrument (MDI): Assessing children's well-being and assets across multiple contexts, Social Indicators Research, 114, 345-369.

Schonert-Reichl, K. A., \& Hymel, S. (1996). Promoting social development and acceptance in the elementary classroom. In J. Andrews (Ed.) Teaching students with diverse needs (pp. 152-200) Scarborough, ON: Nelson Canada.

Schonert-Reichl, K. A., Hanson-Peterson, J. L., \& Hymel, S. (2015). Social and emotional learning and pre-service teacher education. In J. Durlak, R. Weissberg, C. Domitrovich, \& T. Gullotta (Eds.), Handbook of social \& emotional learning: Research and practice (pp. 406-421). NY: Guilford. 
Sklad, M., Diekstra, R., De Ritter, M., \& Ben, J. (2012). Effectiveness of school-based universal social, emotional, and behavioural programs: Do they enhance students' development in the area of skill, behaviour, and adjustment? Psychology in the Schools, 49, 892-909.

Sklad, M., Diekstra, R., De Ritter, M., Ben, J.\& Gravesteijn, C. (2012). Effectiveness of school-based universal social, emotional, and behavioural programs: Do they enhance students' development in the area of skill, behaviour, and adjustment? Psychology in the Schools, 49, 892-909.

Smetanin, P., Stiff, D., Briante, C., Adair, C., Ahmad, S., \& Khan, M. (2011). The life and economic impact of major mental illnesses in Canada: 2011 to 2041. Risk Analytica, on behalf of the Mental Health Commission of Canada. Retrieved from www.mentalhealthcommission.ca/.../MHCC_Report_Base_Case_FINAL_ENG_0_0.pdf

Stewart, L. A., Harris, A., Archambault, K., Wilton, G., Cousineau, C., Varrette, S., \& Power, J. (2009). An initial report on the results of the pilot of the computerized mental health intake screened system (CoMHISS). Ottawa: Correctional Service of Canada. Retrieved from http://strategy.mentalhealthcommission.ca/the-facts/

Suldo, S. M. (2016). Promoting student happiness: Positive psychology interventions in schools. NY: Guilford.

Waddell, C., McEwan, K., Shepherd, C. A., Offord, D. R., \& Hua, J. M. (2005). A public health strategy to improve the mental health of Canadian children. The Canadian Journal of Psychiatry, 50(4), 226-233.

Weare, K. (2000). Promoting mental, emotional and social health: A whole school approach. London, UK: Routledge.

Weare, K. (2010). Mental health and social and emotional learning: Evidence, principles, tensions and balances. Advances in School Mental Health Promotion, 3, 5-17.

Wells, J., Barlow, J., \& Stewart-Brown, S. (2003). A systematic review of universal approaches to mental health promotion in schools. Health Education Journal, 103, 197-220.

World Health Organization. (2010). Mental health: Strengthening our response. Fact sheet No. 220. Retrieved from http://www.wiredhealthresources.net/resources/NA/WHOFS_MentalHealthStrengtheningResponse.pdf

Zins, J. E., Bloodworth, M. R., Weissberg, R. P., \& Walberg, H. J. (2004). The scientific base linking social and emotional learning to school success. In J. E. Zins, R. P. Weissberg, M. C. Wang, \& H. J. Walberg (Eds.), Building academic success on social and emotional learning: What does the research say? (pp. 3-22). NY: Teachers College Press. 